\title{
Mixed Outbreak of Falciparum and Vivax Malaria and Dengue Fever Among the Egyptian Five-a-Side Ball Team Returning From Nigeria After Participation in the African Cup of Nations (Egypt, July 2021)
}

\author{
Mohamed Gouda ${ }^{1}$; Salma Afifi ${ }^{2}$; Sahar Zamy ${ }^{2}$; Hanaa Abu El Sood ${ }^{2}$; Alaa Eid ${ }^{2}$ \\ ${ }^{1}$ Port Said Directorate, Port Said, Egypt \\ ${ }^{2}$ Ministry of Health, Cairo, Egypt
}

Corresponding Author:

Mohamed Gouda

Port Said Directorate

Port Said, 42511

Egypt

Phone: 201062421237

Email: mohamed.n.gouda@gmail.com

\section{Abstract}

Background: On July 28, 2021, the Port Saeed health directorate was reported of a team member of the Egyptian five-a-side ball team who was admitted to the Port Saeed Fever Hospital on the same day with acute onset of high fever, headache, malaise, and delirium. The patient has recently returned from Nigeria with his teammates after participation in the African Cup of Nations. On asking the patient about other cases among his teammates, he informed of 1 who started to feel sick in Nigeria and was quarantined in the Abasia Fever Hospital in Cairo and another 2 who were currently at their homes in Port Saeed.

Objective: This study aims to confirm an outbreak, identify possible causes, and implement necessary control measures.

Methods: All 26 team members were contacted in their governorates. Active case finding among them and their contacts was performed using sensitive case definition. A case was defined as anyone from the Egyptian five-a-side ball team returning from Nigeria or their contacts who complained of sudden onset of fever, malaise, or respiratory or gastrointestinal symptoms. Symptomatic patients were swabbed for SARS-CoV-2 by reverse transcription polymerase chain reaction (RT-PCR). Blood samples were collected for malaria film and immunoglobulin M (IgM) for dengue testing.

Results: Of 26 team members, 7 (27\%) complained of symptoms, with an attack rate of $26.9 \%$. Their mean age was $37.1(8.6)$ years, and all of them were males. Of the 7 cases, $6(86 \%)$ were from Port Saeed, their clinical symptoms ranged from fever $(\mathrm{n}=3$, $43 \%)$ malaise $(n=7,100 \%)$, headache $(n=4,57 \%)$, nausea $(n=3,43 \%)$, and delirium $(n=1,14 \%)$. Laboratory testing confirmed 4 (57\%) cases with malaria falciparum, including 1 (14\%) positive for COVID-19. In addition, the blood film of 2 (28\%) patients showed malaria falciparam and vivax, and $1(14 \%)$ patient was positive for SARS-CoV-2 and dengue. All patients recovered and were discharged from the hospitals. Patients did not receive malaria prophylaxis before traveling, and they were sleeping in tents near a forest, where they exposed to mosquito bites. A vector survey was performed, and mosquito spraying and larvae destruction near the residential areas of all team members were implemented.

Conclusions: An outbreak of malaria and dengue occurred among the Egyptian five-a-side ball team that recently returned from Nigeria. The outbreak was caused by defective malaria-preventive measures with no prophylaxis. Outbreak was controlled through early patient detection, isolation, and treatment. In addition to entomological and environmental preventive measures, it is necessary to ensure that all sports teams traveling to malaria- and dengue-endemic areas receive prophylaxis and apply protective measures against mosquito bites.

(iproc 2022;8(1):e36599) doi: $\underline{10.2196 / 36599}$

\section{KEYWORDS}

malaria; dengue; COVID-19; mixed infection 
Edited by Y Khader; this is a non-peer-reviewed article. Submitted 18.01.22; accepted 19.01.22; published 07.02.22.

Please cite as:

Gouda M, Afifi S, Zamy S, Abu El Sood H, Eid A

Mixed Outbreak of Falciparum and Vivax Malaria and Dengue Fever Among the Egyptian Five-a-Side Ball Team Returning From

Nigeria After Participation in the African Cup of Nations (Egypt, July 2021)

iproc 2022;8(1):e36599

URL: https://www.iproc.org/2022/1/e36599

doi: $10.2196 / 36599$

PMID:

CMohamed Gouda, Salma Afifi, Sahar Zamy, Hanaa Abu El Sood, Alaa Eid. Originally published in Iproceedings (https://www.iproc.org), 07.02.2022. This is an open-access article distributed under the terms of the Creative Commons Attribution License (https://creativecommons.org/licenses/by/4.0/), which permits unrestricted use, distribution, and reproduction in any medium, provided the original work, first published in Iproceedings, is properly cited. The complete bibliographic information, a link to the original publication on https://www.iproc.org/, as well as this copyright and license information must be included. 